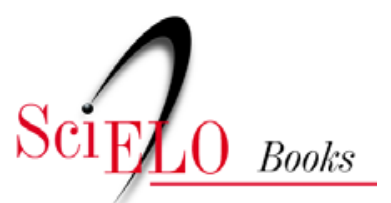

\title{
O processo de socialização profissional na medicina
}

\author{
Sergio Rego
}

\section{SciELO Books / SciELO Livros / SciELO Libros}

REGO, S. O processo de socialização profissional na medicina. In: MACHADO, M.H., org. Profissões de saúde: uma abordagem sociológica [online]. Rio de Janeiro: Editora FIOCRUZ, 1995, pp. 119-132. ISBN: 978-85-7541-607-5. Available from: doi: 10.7476/9788575416075.008. Also available in ePUB from: http://books.scielo.org/id/t4ksj/epub/machado-9788575416075.epub.

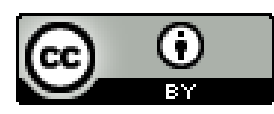

All the contents of this work, except where otherwise noted, is licensed under a Creative Commons Attribution $\underline{4.0 \text { International license. }}$

Todo o conteúdo deste trabalho, exceto quando houver ressalva, é publicado sob a licença Creative Commons Atribição 4.0.

Todo el contenido de esta obra, excepto donde se indique lo contrario, está bajo licencia de la licencia Creative Commons Reconocimento 4.0. 


\section{O processo de socialização profissional na medicina}

Sergio Rego

Neste texto, baseado em minha dissertação de mestrado apresentada ao Instituto de Medicina Social da UERJ (Rego, 1994), procuramos trazer à discussão sobre as profissões de saúde a questão da formação profissional em medicina, a educação médica questionada a partir do referencial teórico da sociologia das profissões. Embora versando sobre a profissão médica, as análises aqui apresentadas podem ser extrapoladas para outras profissões da saúde. Sendo assim, apresentamos inicialmente, de forma sucinta, o conceito de socialização profissional, fundamentando-o nas observações de Merton (1957). Em seguida, apresentamos uma pequena descrição sobre as características do ensino prático em alguns países, introduzindo assim a questão da formação prática como um aspecto privilegiado para a análise. Posteriormente, é destacada a importância de ultrapassarmos os limites das experiências curriculares quando do estabelecimento dos campos de seu estudo, analisando-se algumas características dos estágios que ocorrem com autonomia em relação ao currículo formal da faculdade.

\section{O processo de socialização}

O debate sobre a formação profissional do médico não pode limitar-se à discussão dos aspectos inerentes à sua base técnica. Ser médico implica estabelecer relações com clientes que necessitam confiar não apenas no conhecimento técnico do profissional, como também ter a certeza de que será respeitado em sua privacidade. Em seu dia-a-dia profissional ele se relacionará com colegas da mesma especialidade, de outras que o apoiarão em sua atuação, e com uma vasta gama de outros trabalhadores que compõem a moderna equipe de saúde. Orientando a conduta do médico existe um conjunto de idéias, valores e padrões que são compartilhados e transmitidos entre os membros da corporação. Estas normas e 
padrões definem características de atitudes e condutas técnicas morais, apontando o que é desejável, permitido ou proscrito, codificando os valores da profissão.

A socialização de adultos inclui mais do que habitualmente é descrito como educação e treinamento, sendo útil pensar no processo de aquisição da função em duas classes principais: aprendizado direto através do ensino didático de um ou outro tipo e indireto, no qual atitudes, valores, padrões de comportamento são adquiridos como subprodutos do contato com instrutores e pares, com pacientes e com membros da equipe de saúde. (Merton, 1957) É claro que nem tudo o que é ensinado nas escolas médicas é aprendido pelos estudantes, assim como nem tudo que eles aprendem é ensinado lá. Este processo está fundamentado não apenas na observação e assimilação do padrão ou mesmo do exemplo deliberado, mas também - e pode ser a forma mais duradoura de aprendizado indiretamente como resultante de seu envolvimento naquela sociedade de staff médico, colegas estudantes e pacientes que constituem a escola médica como uma organização social.

Assim, a faculdade costuma ser identificada como elemento crucial na aprendizagem profissional, porque representa o contexto institucional no qual se inicia a socialização. Esta importância lhe é atribuída por constituir não somente o ambiente onde se transmitem os conhecimentos, experiências, hábitos, atitudes e valores, mas também o meio pelo qual os membros da profissão controlam o que seus colegas serão e o nível de aprendizagem que recebem. Este papel, crucial na forma como é descrito, é atribuído à escola médica. É nos estágios (que, pelo menos no Brasil, não estão previstos em seu currículo formal) e na prática regularmente oferecida pela faculdade que o estudante é efetivamente forjado como profissional, onde adquire segurança para iniciar-se de fato na prática da profissão que escolheu. Nas atividades práticas do estudante ele desenvolve seu 'eu-profissional', com seus valores característicos, atitudes, conhecimento, e habilidades, fundindo-os em disposições mais ou menos consistentes que orientam seu comportamento em uma ampla variedade de situações profissionais ou não (Merton, 1957).

\section{A prática na formação do médico}

Embora a experiência clínica seja componente essencial do treinamento médico, até agora, enquanto os currículos especificam a duração 
e o tipo de expiosição clínica que é esperado que os alunos tenham, existem relativamente poucas informações sistematizadas sobre o que constitui a experiência clínica e o que ela proporciona ao estudante. Assim, para conhecermos o processo de socialização profissional dos estudantes de medicina, é preciso conferir uma atenção toda especial ao aprendizado prático deste aluno. Aqui veremos uma breve descrição sobre algumas características do ensino prático em alguns países, com um destaque especial para o caso do Brasil e a importância que a questão dos estágios extracurriculares ${ }^{1}$ para o tema.

$\mathrm{Na}$ análise da descrição da situação do ensino médico na Inglaterra e nos Estados Unidos no período anterior a 1910 pode-se facilmente reconhecer algumas características também assinaladas no Parecer 506/69 do Conselho Federal de Educação do Brasil, como será visto adiante. Segundo Coe (1984) "tanto nas universidades inglesas como nas dos Estados Unidos os estudantes assistiam a umas poucas lições, com freqüência perseguiam interesses independentes e aprendiam a maior parte de seus conhecimentos acompanhando aos médicos em suas visitas às salas do hospital. Os exames versavam em sua maior parte sobre os conhecimentos de ciências básicas e deixavam pouco lugar para a aplicação destas (...$)$. Os programas eram muito flexíveis e, exceto em alguns casos, era permitido aos estudantes procurarem o seu próprio ensino".

Esta situação, nos Estados Unidos especialmente, "começa a ser revertida após o Relatório Flexner, ${ }^{2}$ marco fundamental na evolução do ensino médico. O ensino médico, até então pouco padronizado, é incorporado às universidades e inclui-se o hospital como local fundamental do ensino prático, criando-se os clerkships como eixo do ciclo clínico.

O clerkship representa o modelo central de ensino no ciclo profissional na maioria das escolas americanas estabelecido com a implantação das recomendações contidas no Relatório Flexner. São curtos ciclos de estágios em serviços dos hospitais universitários ou conveniados, com os estudantes divididos em pequenos grupos, quando eles envolvem-se efetivamente com a rotina de atividades do serviço. Incluem-se plantões durante a semana e fim de semana, sendo os alunos responsáveis por parte da rotina de atendimento de internação e evolução dos pacientes. Por

1 Considerando currículo como a soma de experiências vividas pelo educando sob os auspícios e direção da escola, define-se estágio extracurricular como todas as atividades de prática clínica ou cirúrgica cumprida pelo aluno que não ocorram desta forma.

2 Flexner, A. Medical Education in the United States and Canada: A Report to the Carnegie Foundation for the Advancement of Teaching, New York, Carnegie Foundation, 1910. 
serem grupos pequenos há intensa participação dos alunos em todas as atividades e um convívio intenso com o professor, internos e residentes.

Os estudos realizados sobre o ensino médico nos Estados Unidos demonstram, em geral, uma intensa dedicação dos estudantes às atividades discentes, especialmente no ciclo clínico. ${ }^{3} \mathrm{O}$ trabalho de Becker (1984) descreve minuciosamente as atividades do estudante nas enfermarias e ambulatórios sugerindo a participação intensa do estudante nos procedimentos diagnósticos e terapêuticos. Este comportamento irá variar de acordo com o tipo de hospital em que o estudante esteja lotado para o clerkship. Quando esta prática ocorre em um hospital com pacientes particulares dos docentes a autonomia do estudante parece fortemente limitada, enquanto durante o clerkship nos hospitais dos veteranos de guerra (públicos, por conseguinte) eles tendem a desempenhar tarefas mais importantes. Apesar disso, o próprio autor encarrega-se de esclarecer o real papel desempenhado pelo corpo discente, afirmando que os estudantes do Kansas não assumem atividades específicas dos graduados principalmente porque o sistema do qual eles participam não permite que eles o façam. Eles ainda não são médicos (...)(Becker, 1987). Não está em questão se eles desejariam ou não assumir tarefas restritas aos profissionais, mas a proibição estrita que decorre do forte sistema de responsabilidade profissional existente naquele país. Os responsáveis legais pelos atos do estudante são o seu supervisor direto, a administração do estabelecimento onde o ato legal vier a acontecer e, finalmente, o próprio estudante.

Por tratar a questão da prática na graduação de uma forma bastante

3 Na pesquisa de campo que realizamos recentemente e que deu origem a nossa dissertação de mestrado junto ao IMS/UERJ, na qual está baseado este texto, não foi incluída a análise de como os estudantes utilizam seu tempo. Entretanto, foi possivel acompanhar, a grosso modo, como se dá o cumprimento formal da carga horária de ensino. E o que foi observado é que o horário formal dessas atividades raramente era cumprido. Várias e várias vezes nossa equipe procurou estar presente próximo ao horário previsto para o fim das aulas práticas e simplesmente não encontrávamos mais ninguém. Posteriormente, orientados pelos alunos, pudemos constatar que muitas dessas aulas, apesar de terem uma previsão de durarem cerca de quatro horas, raramente ultrapassavam a primeira. Entretanto, uma análise da disponibilidade de tempo dos estudantes da maior parte de nossas escolas nos levaria, talvez, àquela mesma conclusão - formalmente os alunos praticamente não têm tempo disponível. Por outro lado, pelo menos desde que o aluno começa a freqüentar o estágio de internato, ele passa (informalmente) a ter direito ao que no mundo profissional dos médicos é chamado de day-off - em um dia da semana o estudante é liberado de suas atividades no internato para freqüientar um plantão. Esta prática, apesar de não existir legalmente nem para os profissionais formados, é tolerada sem críticas no serviço público em geral. 
peculiar, merece referência o modelo implementado em Cuba. Embora a estrutura do curso seja muito semelhante à brasileira (seis anos de duração; quatro semestres iniciais de ciclo básico; internato nos dois últimos semestres do curso) a escola médica cubana incorporou elementos mais característicos dos clerkships americanos a realização de plantões noturnos nos serviços clínicos, higiênicos e epidemiológicos com uma duração de 6-8 horas a partir do terceiro ano (Cuba, 1993). Da mesma forma, o trabalho independente e a responsabilidade clínico-epidemiológica é quase total no internato com supervisão e controle por parte do docente. A valorização da aquisição de habilidades práticas no modelo cubano pode ser observada pela exigência de aprovação prévia nos exames práticos para prestar os teóricos.

A importância conferida pelos especialistas da Comissão de Ensino Médico do MEC à prática na formação do estudante está bem expressa no documento divulgado em 1974 ao afirmarem, categoricamente, que a componente essencial da formação do estudante de medicina reside nas características do atendimento dos pacientes no ambiente hospitalar, do qual participa na qualidade de estagiário ou de interno(Comissão de Ensino Médico, 1974). Determinava ainda que a formação do médico incluísse, obrigatoriamente, a participação nos trabalhos de unidades de saúde de vários tipos, com desempenho, pelo estudante, de tarefas de crescente complexidade, sempre na dependência da aptidão correspondente a cada qual das fases sucessivas da aprendizagem. Durante esse período, o aluno amplia seus conhecimentos relativos às bases doutrinárias do exercício da medicina, inicia a aquisição de habilidades psicomotoras necessárias à profissão, e, ainda mais, adquire atitudes que definirão sua conduta dentro de padrões éticos consagrados, no tocante ao seu relacionamento com os pacientes, às respectivas famílias e os demais integrantes da equipe de saúde

Esta é, portanto, a componente essencial da transformação do estudante em médico. É a procura por adquirir a experiência clínica uma das principais forças que mobilizam os alunos em seu período de formação já que os estudantes querem ver pacientes com doenças que eles esperam tratar freqüentemente após a formatura. A valorização da prática na formação do médico está clara também no trabalho de Merton (1957) ao afirmar que "deste ponto de vista, estudantes de medicina estão engajados em estudar as funções profissionais do médico através da combinação tanto de seu componente de conhecimento, habilidades, atitudes e valo- 
res, como em serem motivados e habilitados para desempenhar este papel num estilo social e profissionalmente aceitável".

Uma característica da estrutura dos cursos de medicina no Brasil, ainda sob forte influência dos princípios propugnados na Reforma Flexner nos E.U.A., é a separação entre o ciclo básico e o ciclo clínico, com a introdução tardia da prática clínica. Assim, os alunos passam os dois primeiros anos do curso envolvidos com as chamadas disciplinas básicas e, a partir do terceiro ano passam a freqüentar o hospital. No hospital estarão envolvidos, com alunos do último ano e residentes, na evolução ${ }^{4}$ diária do paciente. Esta participação é discreta, já que tanto internos quanto residentes, superiores na hierarquia do hospital, tem precedência. Entretanto, como destaca Santana (1989), o contexto do ensino, seu campo de prática real como processo de qualificação para o trabalho é, predominantemente, o hospital. (...) é no hospital, através de suas práticas assistenciais progressivamente custosas do ponto de vista econômico e historicamente excludentes sob o aspecto social, que se concentram as experiências marcantes e definidoras na formação médica.

As aulas práticas da grande maioria das disciplinas reforçam esse papel de observadores que é característico dos estudantes dos primeiros anos nos hospitais de ensino. Na realidade, será apenas quando iniciarem o internato que os alunos estarão envolvidos diretamente na assistência do paciente. Até então, mesmo durante as experiências nas enfermarias, os alunos apontam sua participação como pouco relevante. Deve-se lembrar, entretanto, que apesar de toda relevância que é dada formalmente ao ensino prático e à prática, oficialmente o estágio só começará no último ou penúltimo ano do curso (quando do início do internato), apesar da grande motivação que todo estudante apresenta em lidar com pacientes. Embora pudesse ser introduzido o contato precoce com pacientes, com as funções de médico e dos serviços de saúde, que seguramente estimulariam o interesse do aluno por aprender outros aspectos menos chamativos, a maioria das escolas de medicina ainda postergam para os últimos anos o contato do estudante com pacientes.

Atento à essa discussão, Barbosa (1986) salienta que locus privilegiado da educação médica é a comunidade e suas instituições, onde se desenrolam os dramas quotidianos (...). Em conseqüência, o aluno deverá ser inserido nos serviços de saúde desde o primeiro ano do curso, elimi-

4 A evolução do paciente consiste no exame clínico matinal (consistindo de uma entrevista e um exame físico direcionado para as alterações relacionadas com a evolução da enfermidade que o paciente seja portador), com a respectiva anotação no prontuário do paciente. 
nando-se a figura simbólica do Estágio Curricular e outras ficções em vigor nos modelos clássicos de ensino. Participando das ações diretas de saúde o aluno despertará gradativamente para os grandes problemas de sua região (...). A aula informativa deixa de ser predominante. Oportunamente, Santana (1989) alerta que com freqüência fala-se na necessidade de "expor o aluno à realidade dos serviços de saúde" e, comumente, a proposta de estágios não vai além de uma "exposição" onde espera-se que a "natural" interação entre aprendiz e praticante ou tutor resulte "espontaneamente" no domínio de habilidades pelo primeiro. Questionamentos como esses ocorrem há vários anos, sendo muito raro que encontremos autores que advoguem sua manutenção. A cada dez anos, aproximadamente, surgem novas propostas reformadoras e é possível contabilizarmos diversas tentativas isoladas de reforma nas mais variadas universidades. A maior parte delas, entretanto, não conseguiu ultrapassar os limites de uma mera reforma curricular, onde os diferentes interesses e a disputa por poder entre os diversos departamentos e especialidades reduzem sensivelmente seu alcance.

Embora a mais importante reforma nos Estados Unidos tenha se dado no início do século, diversos outros modelos de ensino já surgiram, muitos criticando o adotado naquela reforma. Estes movimentos inovadores tiveram sua origem tanto em faculdades de medicina como em organismos internacionais sediados naquele país. Modelos como o da medicina comunitária, ensino integrado ou mesmo a integração docenteassistencial, tiveram grande influência sobre a crítica ao ensino médico no Brasil, sendo progressivamente absorvidos na América Latina.

Ainda que seja comum o reconhecimento de que o ensino médico se dá, preferencialmente, nos serviços de saúde e que nenhum profissional aprende seu ofício apenas nas salas de aula, com lápis e cadernos, sendo necessário aprender a exercer a profissão dentro da sociedade, com os problemas e dilemas que ela oferece e, no caso específico do médico, dentro dos serviços de saúde, isto ainda pode ser percebido juridicamente. A legislação vigente no Brasil impede que os serviços participem da condução do processo de ensino, considerados ainda como de responsabilidade exclusiva do aparelho formador. A rede prestadora de serviços de saúde é mera coadjuvante na formação, limitando-se a absorver acriticamente estagiários que tanto podem ser vistos como estorvos como meros auxiliares no atendimento de sua demanda. 


\section{O estágio extracurricular}

É muito comum, ao analisar a crise do ensino médico, atribuir sua responsabilidade à criação de grande quantidade de novas escolas médicas, especialmente durante a década de 1960 e início da de 1970, destacando-se que não houve planejamento adequado para que se preparasse o Corpo Docente para essas escolas e tampouco foi exigido, como prérequisito, a existência de um hospital-escola. Como conseqüência da massificação da formação de médicos teria ocorrido a queda do padrão de ensino e a busca dos estudantes pelos estágios extracurriculares.

A procura dos estudantes por um sistema de ensino informal, entretanto, não é decorrente de transformações sofridas em virtude da expansão da rede de faculdades em geral e escolas médicas em particular, nos anos 60 e 70 ou de uma deterioração na qualidade de ensino nas últimas décadas, como pode ser facilmente constatado em diversos relatos históricos.

A primeira referência oficial que se tem notícia sobre a participação de acadêmicos de medicina em estágios na rede pública no Rio de Janeiro data de 1920 - o regulamento de um posto auxiliar do Pronto Socorro. Já a lei 2.401/21, que estruturou o Departamento Municipal de Assistência Pública, trazia, em seu artigo 77, a exigência de realização de prova de suficiência para a admissão de acadêmicos de $5^{\circ}$ e $6^{\circ}$ anos médicos, além da descrição de suas atribuições.

Já no trabalho de Schraiber (1993), que examina a constituição do trabalho médico especializado e incorporador de tecnologias, é possível encontrar diversos depoimentos de médicos entrevistados que fazem referências a esta prática. A análise da autora busca destacar o papel que este espaço de opção pessoal parece representar no processo de formação profissional. Diz a autora que essa noção [de liberdade] não mais deixará de acompanhá-lo como referencial de pressuposto adequado e qualificador de seu trabalho. (...) Lá pelo meio do currículo escolar, o estudante já constrói no interior do currículo formal o currículo pessoal, aquele que lhe permitirá alcançar qualificações específicas, maior adestramento e experiência clínica, e o diferenciará na profissão, por algum domínio na arte clínica ou da técnica cirúrgica. A importância conferida a esta prática foi bem expressa por um de seus entrevistados (natural do Estado de São Paulo), que afirmou ter optado por cursar a faculdade de medicina no Rio de Janeiro pois em São Paulo era difícil que o estudante pudesse praticar a medicina, praticar no hospital, nos grandes serviços. Para poder trabalhar naquela ocasião tinha de obter uma amizade, alguém que me 
encaminhasse, e como eu não tinha propriamente, então achei por bem... No Rio, realmente o estudante tinha melhores condições de trabalho que o paulista. Não existindo maiores informações sobre a existência desta diferença tão marcante sobre a possibilidade de diferenças tão sensíveis no mercado de trabalho, fica este dado como uma questão para outros estudos.

Referindo-se ao período anterior à Reforma Universitária no Brasil, Gonçalves (1980) afirma que poucos eram os Hospitais de Ensino, e aos alunos dava-se a liberdade e tempo para escolher hospitais da comunidade, públicos ou privados, como os serviços de urgência, que sempre foram e continuam sendo excepcionais campos de aprendizado médico. Um diagnóstico mais preciso desta situação é dado pelo Parecer n ${ }^{\circ}$ 506/69, aprovado pelo Conselho Federal de Educação, que afirmava não haver nenhum médico dos que se formaram no Brasil até aquela época que tenha cumprido senão parcela reduzidíssima dos horários oficialmente estabelecidos pelas escolas. Era praxe, então, vincular-se cada estudante, desde o segundo ou terceiro ano, a determinado serviço clínico, onde, no horário oficialmente destinado ao aprendizado teórico das várias disciplinas, procurava aprender ou exercitar-se nas tarefas necessárias à prática da profissão, com desconhecimento quase completo do programa escolar. Neste Parecer o conselheiro referia-se a este fato como existente apenas em décadas passadas, buscando assim enaltecer as virtudes da Reforma Universitária, que teria promovido tais transformaçōes. Entretanto, contrariando essa visão otimista que o Parecer sugere para o período pós-reforma, foi apresentado um trabalho, no Congresso da Associação Brasileira de Educação Médica em 1972, onde se afirmava que os poucos hospitais de ensino existentes não incorporavam o aluno à sua força de trabalho ou o faziam tardiamente, mediante internato. As alternativas que restavam aos estudantes eram a procura de emprego em clínicas particulares e na rede estadual. (Quadra et al., 1974). Não há, portanto, razões para se acreditar que a atividade extracurricular venha se expandindo nos últimos anos, ou que seja algum sinal recente de insatisfação do aluno com o tipo de ensino ministrado nas faculdades. Esta prática está disseminada há décadas e não há registros de que quaisquer mudanças tenham efetivamente ocorrido em decorrência de alterações curriculares ou reformas administrativas.

É necessário que reflitamos sobre as razões que levaram esta prática tão antiga e tolerada pelos médicos a ter se transformado em algo potencialmente perigoso para a qualidade da formação dos futuros profissio- 
nais. Para esta compreensão é preciso entendermos as modificações observadas nesta relação de ensino, contextualizando-a neste período de profundas transformações no mercado e nas condições de trabalho médico. O que caracterizava essa prática em um tempo não muito distante era a relação tutorial entre discípulo e mestre. Dessa forma, o estudante freqüentava a clínica privada do professor ou prestava serviço na Santa Casa em troca de aprendizado e possibilidades de uma futura clientela. Tal atividade, normalmente realizada lado a lado com o professor, nunca foi considerada como extracurricular, representando efetivamente parte de um bom sistema de aprendizado por preceptoria. As mudanças no mercado, com a redução da atividade liberal pura, aliada ao aumento do número de profissionais e à própria expansão da rede de saúde, tiveram repercussões importantes nas principais características desta atividade, diminuindo muito as possibilidades de existência de uma preceptoria ou supervisão mais efetiva.

Por outro lado. Junqueira (1966), ao referir-se aos atendimentos que ocorriam em meados da década de 1960 nos setores de emergência dos hospitais da Guanabara e à participação dos estudantes neles, fazia uma descrição de uma rotina desinteressante e estafante, onde não há obrigação de ensinamento por parte do corpo clínico, o que é feito só isoladamente e em caráter pessoal por alguns médicos da equipe. Mais uma vez o caráter de um ensinamento relacionado exclusivamente a disposições individuais é reforçado. Não existia qualquer programa de ensino naqueles hospitais que já ofereciam estágios de forma sistemática, . O ensino que por ventura ocorria dependia de relações pessoais, não institucionais.

Diversos outros estudos (Kloetzel, 1976; Oliveira et al., 1989; Pellanda, 1990; Faria et al., 1991; Millan \& Barbedo, 1988; Rego, 1994) demonstraram a importância dos estágios extracurriculares quantitativa e qualitativamente para a formação médica, nos mais diversos estados de nosso país, sempre demonstando seu início precoce em relação ao estágio de internato, a pequena importância atribuída pelos alunos às eventuais remunerações lá obtidas e uma especial predileção pelas Emergências, Maternidades e Unidades de Terapia Intensiva como campos de prática.

Algo está faltando nas atividades desenvolvidas pelos estudantes nas faculdades e que eles estão encontrando, por conta própria, nos serviços de saúde. Este algo mais, traduzido às vezes como botar a mão na massa ou buscar segurança na prática, é um dos aspectos que neste trabalho mais sobressaem na explicação sobre as razões que levam os estudantes a nos 
procurarem. O que eles procuram que não estão encontrando em suas escolas de formação profissional? Para a medicina, o conceito que melhor explica esta busca é o de experiência clínica que, segundo Becker (1984), refere-se à verdadeira experiência em lidar com com pacientes e doenças, e o principal significado desta expressão repousa na polarização implícita com o aprendizado de liuros. Experiência clínica, na visão adotada para este termo, confere ao médico um conhecimento que ainda não foi sistematizado e verificado cientificamente. Não é possível adquirir este conhecimento através do estudo acadêmico - é necessário observar o fenômeno clínico e lidar com os problemas clínicos diretamente. Ela pode inclusive substituir o conhecimento comprovado cientificamente, pode ser usado para legitimar um conjunto de opções de procedimentos para o tratamento de um paciente e, da mesma forma, pode ser usada para contra-indicar alguns procedimentos que tenham sido estabelecidos cientificamente.

Esta experiência só pode ser adquirida com a prática. Ela está intimamente ligada ao conceito de que a medicina é uma Arte, antes de ser uma Ciência. E os estudantes de medicina aprendem cedo a valorizá-la, que só é acumulável com a prática. É ainda Becker que primeiro destacou esta característica e sistematizou suas reflexões. Para ele, os estudantes têm uma pergunta permanentemente norteando suas reflexões: Como posso aproveitar melhor meu tempo para preparar-me para a prática profissional como médico? (Becker, 1984). Uma das respostas apresentadas pelos alunos estaria na perspectiva construída em torno do conceito de experiência clínica e foi por ele sumarizada da seguinte forma: é importante para um médico ter experiência clínica: as atividades na faculdade são boas para sua formação quando dão aos estudantes a oportunidade de adquiri-la ou dão a eles acesso à experiência clínica de seus professores: são ruins quando não fornecem nenhuma dessas coisas: um estudante está fazendo um progresso real em sua preparação para a prática quando ele pode demonstrar para si próprio e para outros que ele absorveu algumas lições da experiência clínica. Nós concluímos, do exame de nossos dados, que os alunos adotam esta perspectiva e organizam seu comportamento por caminhos congruentes com ele (Becker, 1984).

A introdução deste valor na análise dos estágios extracurriculares clareia diversos pontos até então obscuros, como por exemplo o porquê dos alunos afirmarem que buscam estes estágios para: complementar sua formação, aprender o que a faculdade não ensina, aprender a medicina do dia-a-dia, aprender a tratar os pacientes de verdade etc. Estas afirmações 
não são coerentes com uma realidade de pouca atenção por parte de seus supostos supervisores ou professores. Passa a fazer sentido quando se começa a pensar nesse aprendizado como busca de experiência clínica. Uma experiência que é reconhecida por eles como passível de ser adquirida nos locais de grande movimento de pacientes, onde eles poderão ver não um ou dois casos de determinada patologia, mas diversos. Onde eles poderão ver o profissional médico em seu verdadeiro local de trabalho, longe do viés que o hospital universitário cria para suas patologias, por ser de referência para as patologias mais raras e para os casos mais complexos. Este viés não conseguiu ser rompido com os convênios MEC/MPAS da década de 1970 e muito menos com a tentativa de integração ao Sistema Único de Saúde.

Mas não é apenas o viés da clientela que parece interferir na procura por outros campos de prática. Existem também aspectos ligados às relações de ensino, propriamente ditas. É muito freqüente ouvirmos de alunos e mesmo de médicos em geral que a universidade é um local onde não se pode ter dúvidas. Ou que suas dúvidas precisam ser complexas, já que as mais simples deporão contra o estudante, em um ambiente muito competitivo.

\section{Considerações finais}

As discussões sobre o conceito de socialização profissional, aquisição de conhecimento e habilidades específicas da profissão (incluindo a experiência clínica) não apenas confirmam a necessidade de ampliarmos nosso ângulo de visão quando do estudo da educação médica, incluindo as experiências que os alunos vivenciam fora dos limites da escola médica, como também nos levam a refletir sobre o locus da formação profissional e sobre o papel que as instituições formadoras vêm tendo no desempenho de suas funções precípuas. Mas esses são temas ainda a serem aprofundados, sem preconceitos ideológicos ou teóricos.

Tais reflexões já reforçam a importância de uma maior integração entre as universidades e os estabelecimentos que acolhem, oficial ou extra-oficialmente, os estudantes para estágio. Embora não deva haver um excesso de otimismo em decorrência de transformações ainda meramente formais, é alvissareiro que tenha sido incluído na Constituição brasileira o princípio de que compete ao Sistema Único de Saúde a ordenação de recursos humanos. Embora representando um pequeno passo dentro do processo, tem se mostrado um caminho para que as discussões entre sis- 
tema formador e prestador de serviços sejam precipitadas, de uma certa forma catalisando o processo em uma perspectiva mais pragmática.

Esta interface já se dá sobretudo pela iniciativa dos estudantes, que buscam a rede de assistência não universitária como alternativa concreta aos limites impostos pelas faculdades à sua participação direta na atenção médica. As dimensões desta participação tornam indispensável seu estudo para a compreensão do processo de socialização do médico no Brasil e sua regulação, com o estabelecimento de limites estritos na autonomia dos estagiários, como uma salvaguarda para os próprios estudantes e para a população usuária daqueles serviços.

\section{Bibliografia}

BARBOSA, F. S. Integração da escola médica com o sistema de atenção à saúde, conferência. Anais do XXIV Congresso Brasileiro de Educação Médica, Florianópolis, UFSC/Abem, 1986, p. 95-104.

BECKER, H. S.; GEER, B.; HUGHES, E. C.; STRAUSS, A., Boys In White: Student Culture. In: A Medical School, 3"Imp., 1"ed. 1961, Chicago, University of Chicago Press, 1984.

COE, R. M. Sociologia de la medicina. 3a. ed., Madrid, Alianza Universidad, 1984.

COMISSÃO DE ENSINO MÉDICO DO MEC, Documento n ${ }^{\circ}$. 2. In: Documentos do ensino médico, 3". ed. 1989, Brasília, MEC, 1974.

CONSELHO FEDERAL DE EDUCAÇÃO. Resolução nº 8 de 8/10/69. In: Currículos mínimos dos cursos de graduação, 4" ed., Brasília, MEC, 1981.

CUBA. La Formación Del Medico General Basico Como Medico De La Familia, Ministerio de Salud Publica, La Habana, Ed. Ciencias Medicas, 1993.

FARIA, J. G. R. et al. Resultados do Projeto 'Relatórios da Medicina'. Avaliação 1 (1) 15-73, Juiz de Fora, UFJF, 1991.

GONÇALVES, G. W. S. Profissão e Educação Médicas, Fortaleza, Imprensa Universitária da UFC, 1980.

JUNQUEIRA, P. C. Importância dos Serviços de Urgência na Formação Médica. Revista Médica do Estado da Guanabara, 1966, 33 (3): 131-135.

KLOETZEL, K. O "Ensino Paralelo" da Medicina. Anais do XIV Congresso Brasileiro de Educação Médica, Rio de Janeiro, Abem, 1976, p. 669-674

MERTON, R. K. Some preliminaries to a sociology of medical education appendix A Socialization: a terminological note 287-293. In: Merton, R. K.; Reader, G. G.; Kendall, P. L. (eds.) The Student-Physician Introductory Studies In The Sociology Of Medical Education, Cambridge, Massachussetts, Harvard University Press, 1957. 
OLIVEIRA, J. A. et al. Ensino Médico e papel das atividades extracurriculares, Revista Saúde em Debate, Londrina, 1989, 25: 35-40.

PELLANDA, L. C. Curriculo oficial e paralelo na Faculdade de Medicina da UFRGS, Porto Alegre, 1990. (mimeo)

QUADRA, A. A. F.; BELACIANO, M. I.; LAZZARO, N. Mercado de Trabalho para acadêmicos de Medicina na Guanabara: análise e proposiçōes. Anais do XII Congresso da Abem, Rio de Janeiro, Abem, 1972.

REGO, S. T. A. A Prática na Formação Médica: os estágios extracurriculares em questão. Dissertação de Mestrado, Instituto de Medicina Social, Universidade do Estado do Rio de Janeiro, RJ, 1994.

SANTANA, J. P. Educação médica e Reforma Sanitária. Saúde em Debate, março de 1989, 7-11.

SCHRAIBER, L. B. O médico e seu trabalho, São Paulo, Hucitec, 1993.

MILLAN, L. R. \& BARBEDO, M. F. Assistência psicológica ao aluno de Medicina: o início de uma experiência. Revista Brasileira de Educação Médica, RJ, 1988, 12 (1): 21-23. 